\title{
Silibinin Inhibits Proliferation, Induces Apoptosis and Causes Cell Cycle Arrest in Human Gastric Cancer MGC803 Cells Via STAT3 Pathway Inhibition
}

\author{
Yi-Xin Wang ${ }^{1 *}$, Hong Cai ${ }^{1}$, Gang Jiang ${ }^{1}$, Tian-Bao Zhou ${ }^{2}$, Hai Wu ${ }^{3}$
}

\begin{abstract}
Background: To investigate the effect of silibinin on proliferation and apoptosis in human gastric cancer cell line MGC803 and its possible mechanisms. Materials and Methods: Human gastric cancer cell line MGC803 cells were treated with various concentration of silibinin. Cellular viability was assessed by CCK-8 assay andapoptosis and cell cycle distribution by flow cytometry. Protein expression and mRNA of STAT3, and cell cycle and apoptosis regulated genes were detected by Western blotting and real-time polymerase chain reaction, respectively. Results: Silibinin inhibits growth of MGC803 cells in a dose- and time-dependent manner. Silibinin effectively induces apoptosis of MGC803 cells and arrests MGC803 cells in the G2/M phase of the cell cycle, while decreasing the protein expression of p-STAT3, and of STAT3 downstream target genes including Mcl-1, Bcl-xL, survivin at both protein and mRNA levels. In addition, silibinin caused an increase in caspase 3 and caspase 9 protein as well as mRNA levels. Silibinin caused G2/M phage arrest accompanied by a decrease in CDK1 and Cyclin B1 at protein and mRNA levels.. Conclusions: These results suggest that silibinin inhibits the proliferation of MGC803 cells, and it induces apoptosis and causes cell cycle arrest by down-regulating CDK1, cyclinB1, survivin, Bcl-xl, Mcl-1 and activating caspase 3 and caspase 9, potentially via the STAT3 pathway.
\end{abstract}

Keywords: gastric cancer - apoptosis - cell-cycle arrest - STAT3 pathway - silibinin

Asian Pac J Cancer Prev, 15 (16), 6791-6798

\section{Introduction}

Gastric cancer (GC) is one of the highest cancermortality diseases with a high incidence rate (Chen et al., 2013), and is the second most common cause of death from cancer in Asia (Leung et al., 2008). Surgery is the cornerstone of the management of patients with resectable GC (Van et al., 2008). For patients with advanced stage GC which are not completely resected, the palliative chemotherapy is the main choice (Karpeh et al., 2013). But many chemicals or drugs have shown numerous side effects. Therefore, developing novel agents to prevent and treat GC specifically for advanced GC, would has potential clinical application value (Marzieh et al., 2013; Kazem et al., 2013).

Numbers of recent studies have demonstrated that signal transducer and activator of transcription (STAT)-3 was constitutively active in various primary tumors and tumor cell lines such as breast cancer, prostate cancer, pancreatic adenocarcinoma, colon carcinoma, as well as GC, activated STAT3 was often associated with tumor invasiveness, metastasis and prognosis by enhancing cancer cells proliferation, survival, and angiogenesis (Yakata et al., 2007; Sato et al., 2011; Morikawa et al., 2011; Singh et al., 2012; Huang et al., 2012; Lee et al.,
2012; Xiong et al., 2012). Meanwhile inhibition of STAT3 activation can suppresse cancer cells growth, invasion and induce cancer cells aopotosis (Ahmad et al., 2012; Sun et al., 2012; Wang et al., 2012; Zhang et al., 2012). Targeting of STAT3 can be achieved by the use of small molecule chemical inhibitors and other plant components or extracts (Sun et al., 2012; Shi et al., 2012; Zhang et al., 2012).

Silibinin has shown strong anticancer efficacy against various cancers including prostate, lung, colon, breast, hepatocellular carcinoma and so on, but the underlying mechanisms are very different in different cancer cells (Wu et al., 2009; Lu et al., 2012; Lin et al., 2012; Yi et al., 2012; Cufi et al., 2013; Oh et al., 2013). The purpose of this stduy was to observe the silibinin's effects in GC cells, to examine whether silibinin modulates STAT3 activation and associated biological response, then to investigate its mechanism in gastric cancer cell lines and determine its therapeutic value in preventing or treating GC.

\section{Materials and Methods}

\section{Cell line}

MGC803, a well differentiated GC line was obtained from Chinese Academy of Medical Sciences Tumor Cell Center (Beijing China). The cells were cultured 
Yi-Xin Wang et al

in RPMI 1640 medium (Gibco, Shanghai, China), supplemented with $10 \%$ fetal bovine serum (FBS) (HyClone Laboratories, Logan, UT) and $1 \%$ penicillinstreptomycin (Nacalai Tesque, Kyoto, Japan), and maintained at $37^{\circ} \mathrm{C}$ in a humidified atmosphere of $5 \% \mathrm{CO}_{2}$.

\section{Reagents}

Silibinin was purchased from Sigma Chemicals (Sigma-Aldrich, Shanghai). Silibinin was dissolved in DMSO (less than $0.1 \%, \mathrm{v} / \mathrm{v}$ ) in experiments. Monoclonal antibodies to STAT3, Phospho-STAT3, Bcl-xL, Mcl-1, Survivin, Caspase-3, Caspase-9, CyclinB1, CDK1 and HRP-labeled goat anti-mouse IgG were purchased from Santa Cruz Biotechnology Incorporation (Santa Cruz, CA, USA). PVDF membrane was obtained from Bio-Rad (CA, USA).

\section{Cell growth assay}

The cellular viability of MGC803 cells was determined by a tetrazolium salt (WST-8)-based colorimetric assay in the Cell Counting Kit-8 (CCK8; Dojindo, Kumamoto, Japan). Briefly, $5 \times 10^{3}$ cells/well were planted in 96well plates and rendered quiescent by incubation in the serum-free medium at $37^{\circ} \mathrm{C}$ for $24 \mathrm{~h}$. MGC 803 cells were treated with control (silibinin $0 \mu \mathrm{M})$ and silibinin at different concentrations $(50,100$ and $200 \mu \mathrm{M})$ and were continuously incubated for 24,48 and $72 \mathrm{~h}$. Subsequently, $10 \mu \mathrm{l} \mathrm{CCK}-8$ solution was added to each well. Then cells were incubated at $37^{\circ} \mathrm{C}$ for $1 \mathrm{~h}$ and the absorbance (A450) was finally read at $450 \mathrm{~nm}$ using a microplate reader. All experiments were performed three times. The cell growth inhibitory rate was calculated as follows: inhibitory rate $(\%)=[1-\mathrm{A} 450($ treated $) / \mathrm{A} 450($ blank $)] \times 100 \%$.

\section{Cell cycle analysis}

For cell-cycle analysis was determined by flow cytometry of propidium iodide (PI) staining. The cells were plated at a density of $5 \times 10^{5}$ per well on a 6 -well plate. The cells were treated with silibinin $(0,50,100$ and $200 \mu \mathrm{M}$ doses) in a humidified atmosphere of $5 \% \mathrm{CO}_{2}$ for $24 \mathrm{~h}$. Then the cells $\left(1 \times 10^{6}\right)$ were collected and washed twice with PBS, and fixed in cold ethanol $(70 \%)$ at $4^{\circ} \mathrm{C}$ overnight. Cells were stained with PI solution $(0.02 \%$ Triton X-100, $50 \mathrm{mg} / \mathrm{mL}-\mathrm{RNase}$ ) for about $30 \mathrm{~min}$ in the dark. Samples were analyzed on a Flow Cytometry. The data acquisition and analysis were performed using MultiCycle software.

\section{Apoptosis assay}

To quantify silibinin-induced apoptotic death of MGC803 cells, annexin V/PI staining was performed followed by flow cytometry.MGC803 cells were treated with silibinin $(0,50,100$ and $200 \mu \mathrm{M})$ in a humidified atmosphere of $5 \% \mathrm{CO}_{2}$ for $24 \mathrm{~h}$. Then the cells $\left(1 \times 10^{6}\right)$ were collected and washed with cold PBS twice, and resuspended in PBS. Then 5ul Annexin V-FITC and 10ul propidium iodide were added to a mixture containing cell resuspension and binding buffer. Finally cells were incubated for $5 \mathrm{~min}$ at room temperature in the dark, and flow cytometry was performed for the quantification of apoptotic cells.

\section{Western blot analysis}

At the end of each treatment, SGC-7901 cells were washed with cold PBS three times and lysed for $30 \mathrm{~min}$ on ice in cell-lysis buffer containing 20mM Tris ( $\mathrm{pH} 7.5$ ), $250 \mathrm{mM} \mathrm{NaCl}, 2 \mathrm{mM}$ EDTA ( $\mathrm{pH} 8.0$ ), $0.1 \%$ TritonX-100, $0.1 \% \mathrm{SDS}, 10 \mu \mathrm{g} / \mathrm{mL}$ aprotinin, $5 \mu \mathrm{g} / \mathrm{mL}$ leupeptin and $0.4 \mathrm{mM}$ PMSF. Protein concentrations were determined via Bradford assay. Protein extracts were resolved by $12 \%$ SDS-PAGE sample buffer. The separated proteins were transferred onto polyvinylidene difluoride membranes (PVDF) for $2 \mathrm{~h}$ at $60 \mathrm{~V}$. The membranes were blocked with $5 \%$ nonfat milk power $(\mathrm{w} / \mathrm{v})$ in TBST $(10 \mathrm{mM}$ Tris, $100 \mathrm{mM} \mathrm{NaCl}$, and $0.1 \%$ Tween-20) overnight at $4{ }^{\circ} \mathrm{C}$. The PVDF was incubated with the specific primary antibodies (dilution ratio $1: 500$ ) for $2 \mathrm{~h}$ at $37^{\circ} \mathrm{C}$, and incubated with horseradish peroxidase-linked antibodies (1:2000 dilution) for $2 \mathrm{~h}$ at room temperature. The washings bands were visualized by ECL detection system and evaluated by densitometry.

\section{Real-time PCR assay}

Total RNA was extracted from cells by the Trizol reagent (Invitrogen, USA). The reverse transcription was performed at $37^{\circ} \mathrm{C}$ for $1 \mathrm{~h}, 45^{\circ} \mathrm{C}$ for $30 \mathrm{~min}$, and $95^{\circ} \mathrm{C}$ for $5 \mathrm{~min}$. Real-time PCR was performed using SYBR green with TaqMan assay (Applied Biosystems Foster City, CA) on a Light Cycler (Roche Applied Science, USA). The sequences of the forward and reverse primers were shown in Table 1. Primers and cDNA were added to SYBR Premix Ex Taq II (Takara Dalian, China), and all the reagents required for PCR were prepared. The PCR cycling conditions were performed for all of the samples as follows: $10 \mathrm{~min}$ at $95^{\circ} \mathrm{C}$ and 40 cycles for the melting $\left(95^{\circ} \mathrm{C}\right.$ for $\left.15 \mathrm{~s}\right)$ and annealing/extension $60^{\circ} \mathrm{C}$ for 1 min steps. The mRNA of every gene expression was normalized to the expressed housekeeping gene $\beta$-actin. The data was analyzed with Light Cycle software 4.0 (Roche Applied Science, USA). Quantification results were expressed in terms of the cycle threshold (CT) value. The CT values were averaged for each triplicate. The ${ }^{\Delta \Delta \mathrm{Ct}}$ value for each gene mRNA was normalized to the value of the $\beta$-actin housekeeping gene mRNA.

\section{Statistical analysis}

All experiments were repeated at least three separate experiments, and the results were expressed as the mean \pm standard deviations. The data were performed by one-way analysis of variance t-test, $\mathrm{X}^{2}$-test and spearman's analysis using SPSS version18.0 (SPSS, Chicago, USA). $P$ value $<0.05$ was considered statistically significant.

\section{Results}

\section{Effect of silibinin on the SGC-7901 cell proliferation}

To observe the effect of silibinin on proliferation of GC cells, MGC803 cells were treated with control (silibinin $0 \mu \mathrm{M}$ ) and silibinin at different concentrations $(50,100$ and $200 \mu \mathrm{M})$ for 24,48 , and $72 \mathrm{~h}$, respectively. The absorbances of MGC803cells were detected with CCK-8 assay. As shown in Figure 1, the treatment with silibinin could inhibit the growth of SGC-7901 cells, and 
Silibinin Inhibits Causes Cell Cycle Arrest in Human Gastric Cancer MGC803 Cells Via STAT3 Pathway Inhibition

the inhibitory effects were in a dose- and time-dependent manner.

\section{Silibinin induced apoptosis of MGC803 cells}

To assess apoptosis ability after silibinin treatment in the MGC803 cells, the apoptosis percentage was detected by flow cytometry assay. As shown in Figure 2, apoptotic cell population increased from $1.4 \% \pm 0.19 \%$ in control to $4.72 \% \pm 0.39 \%, 11.69 \% \pm 0.69 \%$ and $22.25 \% \pm 1.25 \%$ ( $p$ all <0.01) after $24 \mathrm{~h}$ treatment with 50, 100 and $200 \mu \mathrm{M}$ silibinin, respectively. When the MGC803 cells were treated for $48 \mathrm{~h}$, a further increase in percent apoptotic cell population to $31.94 \% \pm 2.74 \%(p<0.01)$ and $49.96 \% \pm 3.78 \%(\mathrm{p} 0.001)$ at 100 and $200 \mu \mathrm{M}$ silibinin concentrations compared with controls, respectively.

Silibinin caused MGC803 cells cycle arrest at G2/M phase

After MGC803 cells were treated with 50, 100 and $200 \mu \mathrm{M}$ of silibinin for $24 \mathrm{~h}$, the proportion of cells at

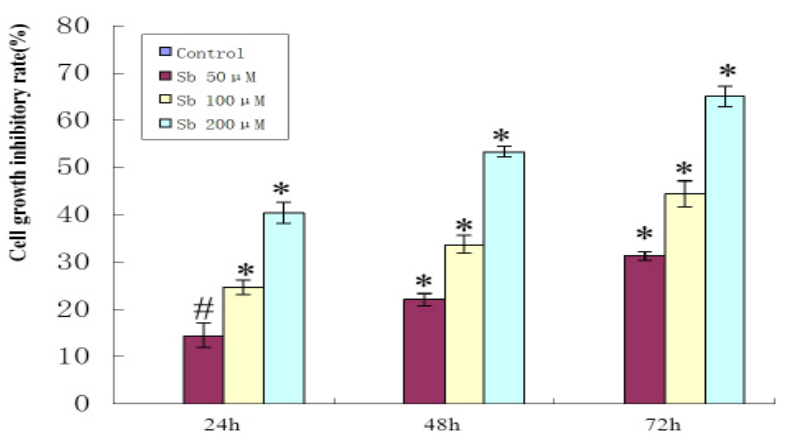

Figure 1. The Cell Growth Inhibitory Rate of MGC803 Cells Treated with Silibinin. MGC803 cells were treated the indicated concentrations of silibinin for $24,48,72 \mathrm{~h}$. The cell growth inhibitory rate was determined by the CCK- 8 assay. All datas were expressed as means \pm SD of three samples for each treatment respectively. ${ }^{\#} p<0.05, * p<0.01$ compared with control. Sb, silibinin
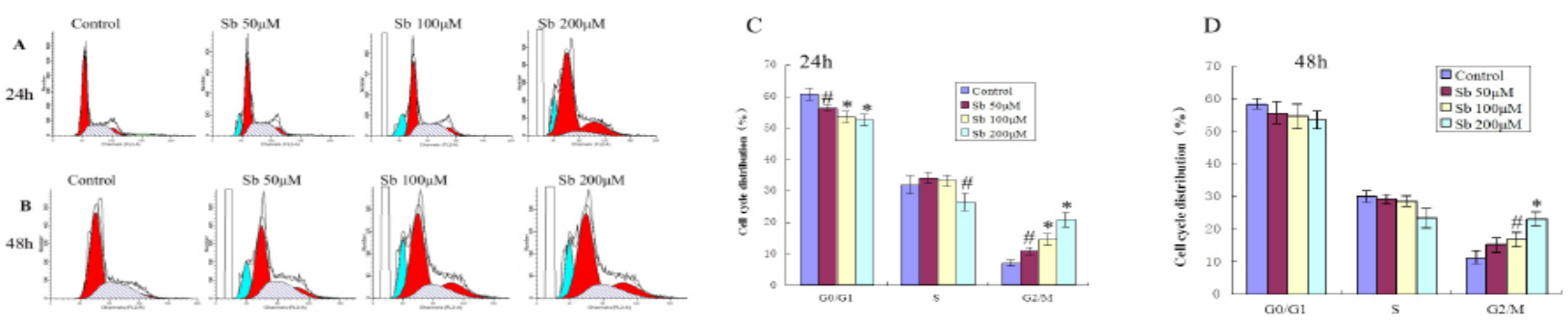

Figure 3. Effects of Silibinin on Cell Cycle in MGC803 Cells. The MGC803 cells were treated with either control or different doses of silibinin $(50,100$ and $200 \mu \mathrm{M})$. After $24 \mathrm{~h}$ and $48 \mathrm{~h}$, cell cycle distribution was analysed by flow cytometry assay, as is shown in Figure 3. A, C: $24 \mathrm{~h} ; \mathrm{B}, \mathrm{D}: 48 \mathrm{~h}$. The data are mean \pm SD of three samples for each treatment respectively. ${ }^{\#} p<0.05$, $* p<0.01$ compared with control. Sb, silibinin

Table 1. Primer Sequences Used in Real-time Quantitative PCR Assay

\begin{tabular}{lll}
\hline Gene & \multicolumn{2}{c}{ Primer Sequence (5'-3') } \\
\hline$\beta$-actin & F:CCCAGCACAATGAAGATCAAGATCAT & R:ATCTGCTGGAAGGTGGACAGCGA \\
STAT3 & F: GGCTTTTGTCAGCGATGG & R:GATTCTGCTAATGACGTTATCC \\
Bcl-xL & F:GCCACTTACCTGAATGACCACC & R: AACCAGCGGTTGAAGCGTTCCT \\
Mcl-1 & F:CTCATTTCTTTGGTGCCTTT & R:CCAGTCCCGTTTTGCCTAC \\
Survivin & F: CTTTCTCAACGACCACCG & R:GTAGGTGACGGGGTGAC \\
caspase 3 & F:CATTGAGACAGACAGTGGTGT & R:CACAAAGCGACTGGATGAAC \\
caspase -9 & F:GTTTGAGGACCTTCGACCAGCT & R: CAACGTACCAGGAGCCACTCTT \\
Cyclin B1 & F:GAAACATGAGAGCCATCCT & R:TTCTGCATGAACCGATCAAT \\
CDK1 & F:TGAAACTGCTCGCACTTG & R:ATGGTAGATCCCGGCTTATT \\
\hline
\end{tabular}


Mcl-1, Bcl-xL, Survivin obviously decreased compared with those of the control group $(p<0.01)$. Real-time PCR assay showed that the expressions of Mcl-1, Bcl-xL, Survivin mRNA obviously decreased compared with those of the control group $(p<0.05)$. While the total STAT3 protein and mRNA levels remained constant during silibinin treatment (Figure 4)

The effects of silibinin on the expressions of caspase 3 and caspase 9

The activation of caspases induce finaly the apoptosis of the cells. The expression of cleaved caspase- 3 and caspase 9 in MGC803 cells treated with different doses of silibinin for $48 \mathrm{~h}$ were measured by western blot analysis, and caspase- 3 and caspase 9 gene levels were measured by real-time PCR. As shown in Figure 5, the level of cleaved caspase- 3 protein was increased in response to 100 and $200 \mu \mathrm{M}$ silibinin $(p<0.01)$, whilie the level of cleaved caspase 9 protein was increased only after treatment with $200 \mu \mathrm{M}$ silibinin $(p<0.01)$, respectively. The data demonstrated that silibinin up- regulated the the expressions of caspase 3 and caspase 9 in a dose-dependent manner. The expressions of caspase 3 and caspase 9 mRNA obviously decreased compared with those of the control group $(p<0.01)$.

\section{Efects of Silibinin on expression of CDK1 and CyclinB 1}

To investigate the mechanism of G2/M cell cycle arrests of MGC 803 cells by silibinin, we tested the protein expression and gene levels of CDK1 and Cyclin B1 which were the two key G2/M cell cycle regulators in MGC803 cells treated with different doses of silibinin for $48 \mathrm{~h}$ by
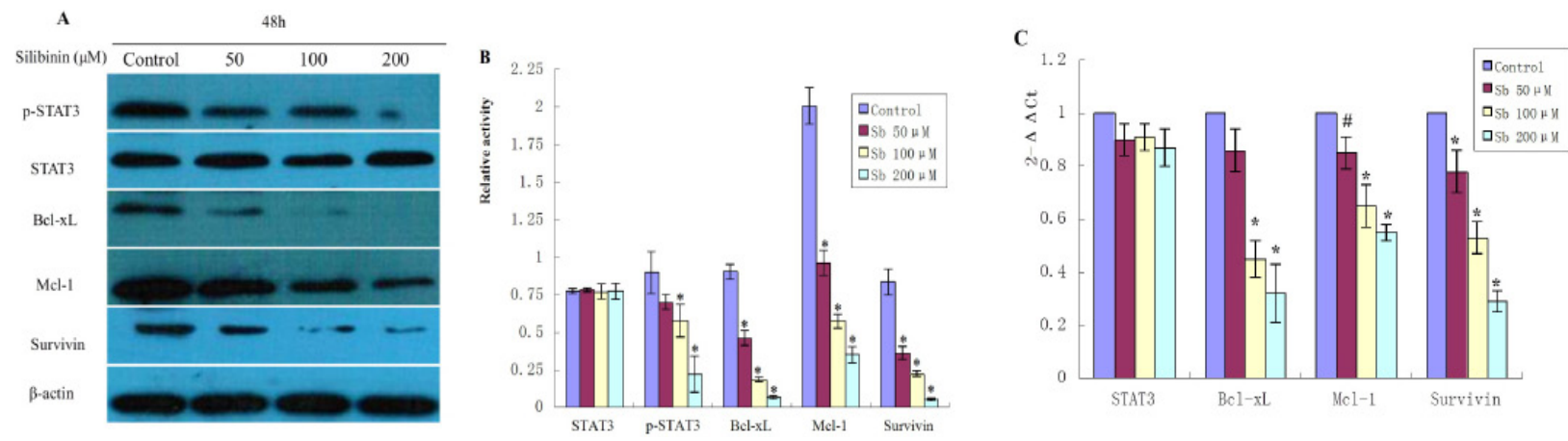

Figure 4. The Effects of Silibinin on the Expression of STAT3, p-STAT3, Bcl-xL, Mcl-1 and Survivin in MGC803

Cells. A) The representative changes of these protein expressions after treatment with different doses of silibinin for $48 \mathrm{~h}$ by western blot analysis. B) Quantitative analysis for these protein levels in MGC803 cells, $\beta$-actin serves as a loading control in the western blot assay. C) Effects of silibinin on STAT3, Bcl-xL, Mcl-1 and Survivin mRNA expression were measured by real-time PCR. The levels of each gene mRNA was normalized to the value of the $\beta$-actin housekeeping gene mRNA. Results obtained from three independent experiments are expressed as means $\pm \mathrm{SD} ;{ }^{*} p<0.05,{ }^{*} p<0.01$, compared with control group. Sb, silibinin

A

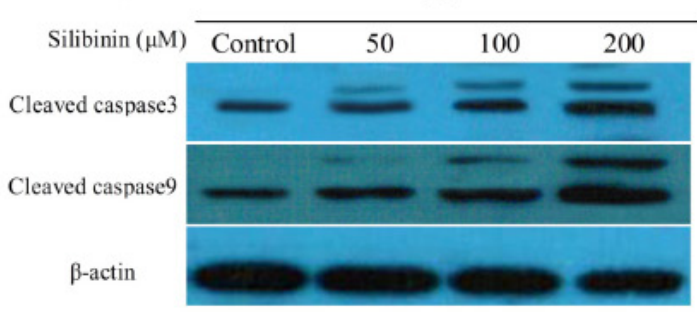

B

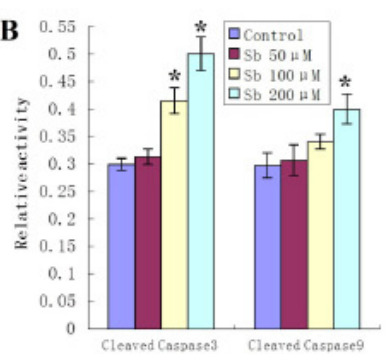

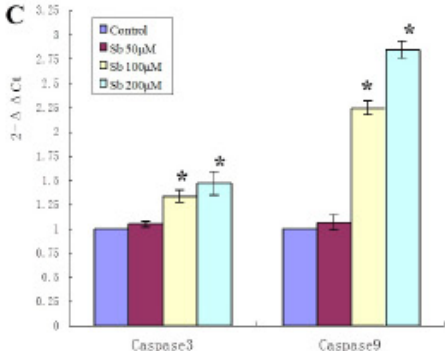

Figure 5. Silibinin Activates the Expression of Caspase 3 and Caspase 9 Protein of MGC803 Cells. A) Expression of cleaved caspase 3 and caspase 9 in MGC803 cells treated with different doses of silibinin for 48 h by Western blot analysis. B) Quantitative analysis for cleaved caspase 3 and caspase 9 protein levels in MGC803 cells, $\beta$-actin serves as a loading control in the Western blot assay. C) Effects of silibinin on caspase 3 and caspase 9 mRNA expression were measured by real-time PCR. The levels of each gene mRNA was normalized to the value of the $\beta$-actin housekeeping gene mRNA. Results obtained from three independent experiments are expressed as mean $\pm \mathrm{SD} ;{ }^{*} p<0.01$, compared with control group. Sb, silibinin
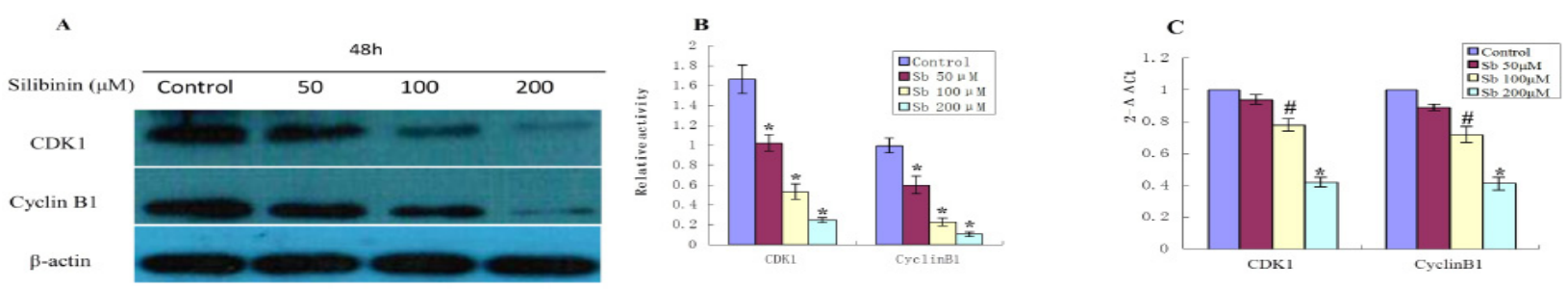

Figure 6. Silibinin Down-Regulates the Protein Expression of CDK1 and Cyclin B1 in MGC803 Cells. A) Expression of CyclinB1 and CDK1 proteins decreased in MGC803 cells treated with silibinin for $48 \mathrm{~h}$ compared with control group by Western blot analysis. B) Quantitative analysis for CDK1 and Cyclin B1 protein levels in MGC803 cells, $\beta$-actin serves as a loading control in the Western blot assay. C: Effects of silibinin on CDK1 and Cyclin B1 mRNA expression were measured by real-time PCR. The levels of each gene mRNA was normalized to the value of the $\beta$-actin housekeeping gene mRNA. Results obtained from three independent experiments are expressed as means $\pm \mathrm{SD} ;{ }^{\sharp} p<0.05,{ }^{*} p<0.01$, compared with control group. Sb, silibinin 
western blot analysis and real-time PCR. As shown in Figure 6, the levels of CDK1 and Cyclin B1 protein and gene were obviously decreased in response to silibinin compared with control group $(p<0.05)$.

\section{Discussion}

Silibinin, a major bioactive component of silymarin flavonolignans extracted from silybum marianum, has been commonly used to treat many liver disorders including hepatitis and cirrhosis, and to protect the liver against poisoning from exposure to chemical toxins and alcohol (Feher et al., 2012). Recently, silibinin has received more attention for its anticancer, chemopreventive efficacy and nontoxic roles in humans (Cheung et al., 2010; Deep et al., 2010; Li et al., 2010). Extensive vitro and vivo studies show that the anticancer role of silibinin by regulating cell proliferation, angiogenesis and metastasis in various cancers (Cui et al., 2012; Wang et al., 2013). A variety of signaling pathways associated with cell proliferation have been identified to be involved in the anticancer actions of silibinin (Singh et al., 2004). Even more attractively is that silibinin shows protective effects against doxorubicin-induced toxicity (Ececen et al., 2011). The aim of this study is to detect whether silibinin works against the MGC803 cells, to investigate the possible mechanisms and the effects of silibinin. The data obtained from the present study show that silibinin strongly inhibited the proliferation of MGC803 cells in a dose- and time-dependent manner, and that this effect was most likely via the induction of apoptosis as well as causing cell cycle arrests in G2/M phase.

Constitutive STAT3 activation has a critical role in tumor development and tumorigenesis in multiple tumors and cell lines. STAT3 may promote cell proliferation and survival, inhibit apoptosis, promote cancer cell invasion and metastasis, increase angiogenesis, which is mediated through regulation of various downstream target genes including c-Myc, JunB, Mcl-1, Survivin, Bcl-2, Cyclin D1, MMP-2 and vascular endothelial growth factor (VEGF) (Stephanou et al., 2000; Masuda et al., 2002; Niu et al., 2002; Gritsko et al., 2006; Ghasemi et al., 2006; Kujawski et al., 2008; Ding et al., 2008; Verschoyle et al., 2008; Lin et al., 2009; Rajamanickam et al., 2010; Fossey et al., 2011; Mateen et al., 2013). Several reports indicated that STAT3 activation contributed to the progression and invasiveness of GC and may be used as a molecular staging biomarker predicting poor prognosis of GC (Devarajan et al., 2013; Yang et al., 2013). Previous studies have established that specific targeting of stomach epithelial STAT3 may be therapeutically effective in preventing gastric carcinogenesis (Hsu et al., 2012), and inhibition of activated STAT3 could reverse resistance to chemotherapy agents in human gastric cancer cells (Kim et al., 2009). Therefore, the inhibition of activated STAT3 signaling pathway may be a potential and effective target for GC therapy.

Apoptosis has been accepted as a fundamental component in the pathogenesis of cancer. The origin of cancer involves deregulated cellular proliferation and the suppression of apoptotic processes, ultimately leading to tumor establishment and growth (Giraud et al., 2012). The selective induction of apoptosis in tumor cells has been increasingly recognized as a promising approach for cancer therapy (Huang et al., 2012). Apoptosis occurs via two main pathways, the extrinsic, or death receptor-mediated pathway and the intrinsic, or mitochondrial-mediated pathway (Hunter et al., 2007; Zhang et al., 2013). Both pathways converge to a final common pathway involving the activation of caspases, which can cleave the regulatory and structural molecules, and thus induce the death of the cells (Hunter et al., 2007). Bcl-2 family members, including Bcl-xl, Mcl-1 and other molecules, play major roles in regulating the intrinsic mitochondrial pathways. Inhibition of multiple Bcl-2 family members will be necessary to achieve optimal therapeutic effect (Ghobrial et al., 2005). In this study, our data shown that silibinin inhibits constitutively active STAT3 phosphorylation and siginificantly downregulate the expression of STAT3regulated gene products, including $\mathrm{Bcl}-\mathrm{xl}$, Mcl-1 both in mRNA and protein level. Meanwhile we found that silibinin treatment significantly activated the caspase-3 and caspase-9. Therefore Silibinin induced apoptosis of MGC803 cells via inhibition of STAT3 signaling pathway along well with down-regulation of Bcl-xL, Mcl-1 and up-regulation of caspase-3 and caspase-9.

Survivin, a member of the family of inhibitor of apoptosis proteins which are known to inhibit both extrinsic and intrinsic pathways of apoptosis by acting as endogenous inhibitors of caspases, functions as a key regulator of mitosis and programmed cell death (Fischer et al., 2005; Giraud et al., 2012). Survivin prominently expressed in transformed cell lines and in all the most common human cancers of lung, gastric, colon, pancreas, prostate and breast (Kang et al., 2009). In vitro and in vivo studies have shown survivin to induce apoptosis, reduce tumor growth potential, and sensitize tumor cells to chemotherapeutic drugs (Hunter et al., 2007). In our experiment, realtime-PCR and Western blot indicates survivin expression is down regulated both at mRNA and protein level in silibinin treated group. So downregulation of survivin might be responsible for apoptosis induction of MGC803 cells by silibinin. All these findings in this study implicated that Silibinin induce apoptosis of MGC803 cells resulted from both the extrinsic and the intrinsic pathway.

It is well known that the cell cycle is segregated into four phases: DNA synthesis ( $\mathrm{S}$ phase) and mitosis (M phase), the $\mathrm{S}$ and $\mathrm{M}$ phases are separated by the two gap phases, G1 (before DNA replication) and G2 (before mitosis). Deregulation of the cell cycle underlies the aberrant cell proliferation that characterizes cancer (Mita et al., 2008). Cancer is frequently considered to be a disease of the cell cycle (Ambrosini et al., 1997). Several studies have suggested that inhibition of cell cycle regulation in cancer cells could be a potential target for the management of cancer (Park et al., 2003; Williams et al., 2012). Collectively, recent studies show that silibinin caused cell cycle arrest in different phases in various cancer cells. Exposure to silibinin resulted in a G1 arrest in human bladder transitional cell carcinoma cells (McDonald et al., 2000) and human prostate cancer DU145 cells (Owa et 
al., 2001). Silibinin treatment aslo inhibited human nonsmall cell lung cancer (NSCLC) cells growth and targeted cell-cycle progressing causing a prominent G1 arrest in dose- and time-dependent manner (Tyagi et al., 2004), but combinations with histone deacetylase inhibitors (HDACi) exhibited a significant $\mathrm{G} 2 / \mathrm{M}$ arrest of the NSCLC cells (Tyagi et al., 2002). Silibinin caused G1 and G2/M cell cycle arrest in human prostate cancer PC3 cells (Mateen et al., 2010). However in the report by Dhanalakshmi S (Mateen et al., 2012), silibinin treatment induced G0/G1 arrest in cell cycle progression of human colon carcinoma HT-29 cells, but higher dose and longer time treatment also caused a G2/M arrest. Further silibinin promotes cell-cycle arrest in G2/M phase in Fet and Geo cell lines and G1 arrest in HCT116 of human colon cancer (Deep et al., 2006). Our study demonstrated that silibinin inhibited the MGC803 cells proliferation by inducing G2/M cell cycle arrest. No significant differences were observed regarding the cell cycle distribution of MGC803 cells in the G0/G1 and S phases. Therefore all these findings implicated that silibinin inhibited different cancer cells in a different manner resulting from the particular selectivity and specificity of its biological responses in various cancer cell types. So it is important to identify the mechanism of silibinin action.

Cell cycle progression and cell division are driven by the sequential activation of a group of serine-threonine kinases called cyclin-dependent kinases (CDKs) (Agarwal et al., 2003). The activity of the CDKs are positively regulated by cyclins and are negatively regulated by cyclin-dependent kinase inhibitors (CDKIs) (Santamaria et al., 2006; Hogan et al., 2007). G2/M transition is regulated by the sequential activation and deactivation of CDK-regulatory proteins and cyclin complexes (Schwartz et al., 2002). The cdc25C functions as a mitotic activator by dephosphorylating CDK1 (cdc2/p34) that forms a complex with Cyclin B1 and drives the cell from G2 to M phase (Malumbres et al., 2009). CyclinB1- CDK1 activation initiates prophase, and that increasing levels of CyclinB1- CDK1 activity trigger different mitotic events. So the regulation of Cyclin B1-CDK1 complex activity is important for proper entry and progression of mitosis (Taylor et al., 2001; Tyagi et al., 2002). According to previous reports, silibinin downregulated cdc25C, CDK1 and Cyclin B1with a concomitant decrease in CDK1 activity in human HT-29 colon carcinoma cells (Mateen et al., 2012) and prostate cancer PC3 cells (Owa et al., 2001), also decreased the level of Cyclins B1 and CDK1 in human colorectal carcinoma LoVo cells (Masuda et al., 2011). Consistent with these reports, in the present study, the realtime PCR and Western blot analysis indicated Silibinin decreased the expression of CDK1 and cyclinB1 both at mRNA and protein level in human MGC803 cells. The molecular alterations caused by Silibinin could have resluted in a G2/M arrest in cancer cells.

According to previous reports, STAT3 has the capacity to promote proliferation through $\mathrm{G} 1$ and $\mathrm{G} 2 / \mathrm{M}$ cell-cycle progression as the common tumor cell- autonomous mechanism that bridges chronic inflammation to tumor promotion (Olivier and Jonathon, 2010). Several agents and genes induce cell cycle arrest and apoptosis in human carcinoma cells via STAT3 signaling pathway (Bollrath et al., 2009; Kaur et al., 2009; Liu et al., 2012). Cucurbitacin $\mathrm{E}$ induces $\mathrm{G} 2 / \mathrm{M}$ phase arrest in human bladder cancer T24 cells through STAT3/p53/p21 signaling (Chetty et al., 2012; Huang et al., 2012; Quoc Trung et al., 2013). Consistent with these observations, the data of our present study show clearly that silibinin caused G2/M arrest was associated with a marked decrease in $p$-STAT3, CDK1 and cyclin B1. Therefore silibinin induce cell cycle arrest may be through STAT3 pathway.

In summary, the findings in present study shown that silibinin inhibited proliferation, induced apoptosis and caused cell cycle arrest at $\mathrm{G} 2 / \mathrm{M}$ phase in human gastric cancer MGC803 Cells. The molecular events identified to be associated with silibinin efficacy include a decrease in $p$-STAT3 and down-regulation of the downstream antiapoptotic proteins Mcl-1, Bcl-xL, Survivin concomitant with up-regulation of caspase 3 and caspase 9, along with a decrease in the cell-cycle regulatory protein cyclin B1 and CDK1. Taken together, the anticancer effects of silibinin in MGC803 cells may be partly achieved via the STAT3 pathway.

\section{References}

Agarwal C, Singh RP, Dhanalakshmi S, et al (2003). Silibinin upregulates the expression of cyclin-dependent kinase inhibitors and causes cell cycle arrest and apoptosis in human colon carcinoma HT-29 cells. Oncogene, 22, 8271-82.

Ahmad A, Sarkar SH, Aboukameel A, et al (2012). Anticancer action of garcinol in vitro and in vivo is in part mediated through inhibition of STAT-3 signaling. Carcinogenesis, 33, 2450-6.

Ambrosini G, Adida C, Altieri DC (1997). A novel anti-apoptosis gene, survivin, expressed in cancer and lymphoma. Nat Med, 3, 917-21.

Bollrath J, Phesse TJ, von Burstin VA, et al (2009). gp130mediated Stat 3 activation in enterocytes regulates cell survival and cell-cycle progression during colitis-associated tumorigenesis. Cancer Cell, 15, 91-102.

Chen XL, Chen XZ, Yang C, et al (2013). Docetaxel, cisplatin and fluorouracil (DCF) regimen compared with non-taxanecontaining palliative chemotherapy for gastric carcinoma, a systematic review and meta-analysis. PLoS One, 8, 60320.

Chetty C, Dontula R, Ganji PN, Gujrati M, Lakka SS (2012). SPARC expression induces cell cycle arrest via STAT3 signaling pathway in medulloblastoma cells. Biochem Biophys Res Commun, 417, 874-9.

Cheung CW, Gibbons N, Johnson DW, Nicol DL (2010). Silibinin--a promising new treatment for cancer. Anticancer Agents Med Chem, 10, 186-95.

Cufi S, Bonavia R, Vazquez-Martin A, et al (2013). Silibinin meglumine, a water-soluble form of milk thistle silymarin, is an orally active anti-cancer agent that impedes the epithelial-to-mesenchymal transition (EMT) in EGFRmutant non-small-cell lung carcinoma cells. Food Chem Toxicol, 60, 360-8.

Cui JW, Li Y, Wang C, Cheng Y, Wei L (2012). Knockdown of a proliferation-inducing ligand (PRIL) suppresses the proliferation of gastric cancer cells. Asian Pac J Cancer Prev, 13, 633-36.

Deep G, Agarwal R (2010). Antimetastatic efficacy of silibinin, molecular mechanisms and therapeutic potential against cancer. Cancer Metastasis Rev, 29, 447-63.

Deep G, Singh RP, Agarwal C, Kroll DJ, Agarwal R (2006). 
Silymarin and silibinin cause G1 and G2-M cell cycle arrest via distinct circuitries in human prostate cancer PC 3 cells, A comparison of flavanone silibinin with flavanolignan mixture silymarin. Oncogene, 25, 1053-69.

Devarajan E, Huang S (2009). STAT3 as a central regulator of tumor metastases. Curr Mol Med, 9, 626-33.

Ding BB, Yu JJ, Yu RY, et al (2008). Constitutively activated STAT3 promotes cell proliferation and survival in the activated B-cell subtype of diffuse large B-cell lymphomas. Blood, 111, 1515-23.

Ececen T, Dost N, culhaci A, et al (2011). Protective effects of silymarin against doxorubicin-induced toxicity. Asian Pac J Cancer Prev, 12, 2697-704

Féher J, Lengyel G (2012). Silymarin in the prevention and treatment of liver diseases and primary liver cancer. Curr Pharm Biotechnol, 13, 210-7.

Fischer U, Schulze-Osthoff K (2005). New approaches and therapeutics targeting apoptosis in disease. Pharmacol Rev, 57, 187-215.

Fossey SL, Bear MD, Kisseberth WC, Pennell M, London CA (2011). Oncostatin M promotes STAT3 activation, VEGF production, and invasion in osteosarcoma cell lines. $B M C$ Cancer, 11, 125.

Ghasemi R, Ghaffari SH, Momeny M, et al (2013). Multitargeting and antimetastatic potentials of silibinin in human HepG-2 and PLC/PRF/5 Hepatoma cells. Nutr Cancer, 65, 590-9.

Ghobrial IM, Witzig TE, Adjei AA (2005). Targeting apoptosis pathways in cancer therapy. CA Cancer J Clin, 55, 178-94.

Giraud AS, Menheniott TR, Judd LM (2012). Targeting STAT3 in gastric cancer. Expert Opin Ther Targets, 16, 889-901.

Gritsko T, Williams A, Turkson J, et al (2006). Persistent activation of stat 3 signaling induces survivin gene expression and confers resistance to apoptosis in human breast cancer cells. Clin Cancer Res, 12, 11-9.

Hogan FS, Krishnegowda NK, Mikhailova M, Kahlenberg MS (2007). Flavonoid, silibinin, inhibits proliferation and promotes cell-cycle arrest of human colon cancer. J Surg Res, 143, 58-65.

Hsu KW, Hsieh RH, Huang KH, et al (2012). Activation of the Notch1/STAT3/Twist signaling axis promotes gastric cancer progression. Carcinogenesis, 33, 1459-67.

Huang C, Huang R, Chang W, et al (2012). The expression and clinical significance of pSTAT3, VEGF and VEGF-C in pancreatic adenocarcinoma. Neoplasma, 59, 52-61.

Huang S, Chen M, Shen Y, et al (2012). Inhibition of activated Stat3 reverses drug resistance to chemotherapeutic agents in gastric cancer cells. Cancer Lett, 315, 198-205.

Huang WW, Yang JS, Lin MW, et al (2012). Cucurbitacin E induces $G(2) / M$ phase arrest through STAT3/p53/ p21 signaling and provokes apoptosis via Fas/CD95 and mitochondria-dependent pathways in human bladder cancer T24 cells. Evid Based Complement Alternat Med, 2012, 952762.

Hunter AM, LaCasse EC, Korneluk RG (2007). The inhibitors of apoptosis (IAPs) as cancer targets. Apoptosis, 12, 1543-68.

Kang MH, Reynolds CP (2009). Bcl-2 inhibitors, targeting mitochondrial apoptotic pathways in cancer therapy. Clin Cancer Res, 15, 1126-32.

Karpeh MS Jr (2013). Palliative treatment and the role of surgical resection in gastric cancer. Dig Surg, 30, 174-80.

Kaur M, Velmurugan B, Tyagi A, et al (2009). Silibinin suppresses growth and induces apoptotic death of human colorectal carcinoma LoVo cells in culture and tumor xenograft. Mol Cancer Ther, 8, 2366-74.

Kazem NK, Abolfazl A, Mohammad PM, Alireza A, Hassan D (2013). Inhibition of leptin and leptin receptor gene expression by silibinin-curcumin combination. Asian Pac
J Cancer Prev, 14, 6595-99.

Kim DY, Cha ST, Ahn DH, et al (2009). STAT3 expression in gastric cancer indicates a poor prognosis. J Gastroenterol Hepatol, 24, 646-51.

Kujawski M, Kortylewski M, et al (2008). Stat3 mediates myeloid cell- dependent tumor angiogenesis in mice. J Clin Invest, 118, 3367-77.

Lee SW,Ahn YY, Kim YS, et al (2012). The Immunohistochemical Expression of STAT3, Bcl-xL, and MMP-2 Proteins in Colon Adenoma and Adenocarcinoma. Gut Liver, 6, 45-51.

Leung WK, Wu MS, Kakugawa Y (2008). Asia pacific working group on gastric cancer. screening for gastric cancer in Asia, current evidence and practice. Lancet Oncol, 9, 279-87.

Li L, Zeng J, Gao Y, He D (2010). Targeting silibinin in the antiproliferative pathway. Expert Opin Investig Drugs, 19, 243-55.

Lin CJ, Sukarieh R, Pelletier J (2009). Silibinin inhibits translation initiation, implications for anticancer therapy. Mol Cancer Ther, 8, 1606-12.

Lin CM, Chen YH, Ma HP, et al (2012). Silibinin inhibits the invasion of IL-6-stimulated colon cancer cells via selective JNK/AP-1/MMP-2 modulation in vitro.J Agric Food Chem, 60, 12451-7.

Liu DB, Hu GY, Long GX, Qiu H, Mei Q, Hu GQ (2012). Celecoxib induces apoptosis and cell-cycle arrest in nasopharyngeal carcinoma cell lines via inhibition of STAT3 phosphorylation. Acta Pharmacol Sin, 33, 682-90.

Lu W, Lin C, King TD, Chen H, Reynolds RC, Li Y (2012). Silibinin inhibits Wnt/ $\beta$-catenin signaling by suppressing Wnt co-receptor LRP6 expression in human prostate and breast cancer cells. Cell Signal, 24, 2291-6.

Malumbres M, Barbacid M (2009). Cell cycle, CDKs and cancer, a changing paradigm. Nat Rev Cancer, 9, 153-66.

Marzieh N, Nosratollah Z, Kazem NK, Mahdieh M (2013). Curcumin and silibinin inhibit telomerase expression in T47D human breast cancer cells. Asian Pac J Cancer Prev, 14, 3449-53.

Masuda H, Fong CS, Ohtsuki C, Haraguchi T, Hiraoka Y (2011). Spatiotemporal regulations of Wee1 at the G2/M transition. Mol Biol Cell, 22, 555-69.

Masuda M, Suzui M, Yasumatu R, et al (2002). Constitutive activation of signal transducers and activators of transcription 3 correlates with cyclin D1 overexpression and may provide a novel prognostic marker in head and neck squamous cell carcinoma. Cancer Res, 62, 3351-5.

Mateen S, Raina K, Agarwal R (2013). Chemopreventive and anti-cancer efficacy of silibinin against growth and progression of lung cancer. Nutr Cancer, 65, 3-11.

Mateen S, Raina K, Jain AK, et al (2012). Epigenetic modifications and p21-cyclin B1 nexus in anticancer effect of histone deacetylase inhibitors in combination with silibinin on non-small cell lung cancer cells. Epigenetics, 7, 1161-72.

Mateen S, Tyagi A, Agarwal C, Singh RP, Agarwal R (2010). Silibinin inhibits human nonsmall cell lung cancer cell growth through cell-cycle arrest by modulating expression and function of key cell-cycle regulators. Mol Carcinog, 49, 247-58.

McDonald ER 3rd, El-Deiry WS (2000). Cell cycle control as a basis for cancer drug development (Review). Int J Oncol, 16, 871-86

Mita AC, Mita MM, Nawrocki ST, Giles FJ (2008). Survivin, key regulator of mitosis and apoptosis and novel target for cancer therapeutics. Clin Cancer Res, 14, 5000-5.

Morikawa T, Baba Y, Yamauchi M, et al (2011). STAT3 expression, molecular features, inflammation patterns, and prognosis in a database of 724 colorectal cancers. Clin 
Cancer Res, 17, 1452-62.

Niu G, Wright KL, Huang M, et al (2002). Constitutive Stat3 activity upregulates VEGF expression and tumor angiogenesis. Oncogene, 21, 2000-8.

Oh SJ, Jung SP, Han J, et al (2013). Silibinin inhibits TPAinduced cell migration and MMP-9 expression in thyroid and breast cancer cells. Oncol Rep, 29, 1343-8.

Olivier G, Jonathon P (2010). Progressive activation of CyclinB1-Cdk1 coordinates entry to mitosis. Dev Cell, 18, 533-43.

Owa T, Yoshino H, Yoshimatsu K, Nagasu T (2001). Cell cycle regulation in the $\mathrm{G} 1$ phase, a promising target for the development of new chemotherapeutic anticancer agents. Curr Med Chem, 8, 1487-503.

Park MT, Lee SJ (2003). Cell cycle and cancer. J Biochem Mol Biol, 36, 60-5.

Quoc Trung L, Espinoza JL, Takami A, Nakao S (2013). Resveratrol induces cell cycle arrest and apoptosis in malignant NK cells via JAK2/STAT3 pathway inhibition. PLoS One, 8, 55183.

Rajamanickam S, Velmurugan B, Kaur M, Singh RP, Agarwal $R$ (2010). Chemoprevention of intestinal tumorigenesis in APCmin/+ mice by silibinin. Cancer Res, 70, 2368-78.

Santamaria D, Ortega S (2006). Cyclins and CDKS in development and cancer, lessons from genetically modified mice. Front Bio Sci, 11, 1164-88.

Sato T, Neilson LM, Peck AR, et al (2011). Signal transducer and activator of transcription-3 and breast cancer prognosis. Am J Cancer Res, 1, 347-55.

Schwartz GK (2002). CDK inhibitors, cell cycle arrest versus apoptosis. Cell Cycle, 1, 122-3.

Shi ZB, Zhao D, Huang YY, et al (2012). Discovery, synthesis, and evaluation of small-molecule signal transducer and activator of transcription 3 inhibitors. Chem Pharm Bull (Tokyo), 60, 1574-80.

Singh N, Hussain S, Bharadwaj M, et al (2012). Overexpression of signal transducer and activator of transcription (STAT-3 and STAT-5) transcription factors and alteration of suppressor of cytokine signaling (SOCS-1) protein in prostate cancer. $J$ Recept Signal Transduct Res, 32, 321-7.

Singh RP, Agarwal R (2004). Prostate cancer prevention by silibinin. Curr Cancer Drug Targets, 4, 1-11.

Stephanou A, Brar BK, Knight RA, Latchman DS (2000). Opposing actions of STAT-1 and STAT-3 on the Bcl-2 and Bcl-x promoters. Cell Death Differ, 7, 329-30.

Sun M, Liu C, Nadiminty N, et al (2012). Inhibition of Stat3 activation by sanguinarine suppresses prostate cancer cell growth and invasion. Prostate, 72, 82-9.

Taylor WR, Stark GR (2001). Regulation of the G2/M transition by p53. Oncogene, 20, 1803-15.

Tyagi A, Agarwal C, Agarwal R (2002). The cancer preventive flavonoid silibinin causes hypophosphorylation of $\mathrm{Rb} /$ p107 and Rb2/p130 via modulation of cell cycle regulators in human prostate carcinoma DU145 cells. Cell Cycle, 1, 137-42.

Tyagi A, Agarwal C, Harrison G, Glode LM, Agarwal R (2004). Silibinin causes cell cycle arrest and apoptosis in human bladder transitional cell carcinoma cells by regulating CDKICDK-cyclin cascade, and caspase 3 and PARP cleavages. Carcinogenesis, 25, 1711-20.

Tyagi AK, Singh RP, Agarwal C, Chan DC, Agarwal R (2002). Silibinin strongly synergizes human prostate carcinoma DU145 cells to doxorubicin-induced growth Inhibition, G2-M arrest, and apoptosis. Clin Cancer Res, 8, 3512-9.

Van Cutsem E, Van de Velde C, Roth A (2008). European Organisation for Research and Treatment of Cancer (EORTC)-gastrointestinal cancer group. Expert opinion on management of gastric and gastro-oesophageal junction adenocarcinoma on behalf of the European Organisation for Research and Treatment of Cancer (EORTC)-gastrointestinal cancer group. Eur J Cancer, 44, 182-94.

Verschoyle RD, Greaves P, Patel K, et al (2008). Evaluation of the cancer chemopreventive efficacy of silibinin in genetic mouse models of prostate and intestinal carcinogenesis, relationship with silibinin levels. Eur J Cancer, 44, 898-906.

Wang J, Chen S, Xu S, et al (2012). In vivo induction of apoptosis by fucoxanthin, a marine carotenoid, associated with downregulating STAT3/EGFR signaling in sarcoma 180 (S180) xenografts-bearing mice. Mar Drugs, 10, 2055-68.

Wang YJ, Niu XP, Li Y, Zhen H, Ma YJ (2013). Effects of celecoxib on cycle kinetics of gastric cancer cells and protein expression of cytochrome c and caspase-9. Asian Pac J Cancer Prev, 14, 2343-47.

Williams GH, Stoeber K (2012). The cell cycle and cancer. $J$ Pathol, 226, 352-64.

Wu KJ, Zeng J, Zhu GD, et al (2009). Silibinin inhibits prostate cancer invasion, motility and migration by suppressing vimentin and MMP-2 expression. Acta Pharmacol Sin, 30, 1162-8.

Xiong H, Du W, Wang JL, et al (2012). Constitutive activation of STAT3 is predictive of poor prognosis in human gastric cancer. J Mol Med (Berl), 90, 1037-46.

Yakata Y, Nakayama T, Yoshizaki A, et al (2007). Expression of p-STAT3 in human gastric carcinoma, significant correlation in tumour invasion and prognosis. Int J Oncol, 30, 437-42.

Yang C, Lee H, Pal S, et al (2013). B cells Promote tumor progression via STAT3 regulated- angiogenesis. PLoS One, 8, 64159.

Yi Qin, Jing Chen, Li Li (2012). Exogenous morphine inhibits human gastric cancer MGC-803 cell growth by cell cycle arrest and apoptosis induction. Asian Pac J Cancer Prev, 13, 1377-82.

Zhang HQ, He B, Fang N (2013). Autophagy inhibition sensitizes cisplatin cytotoxicity in human gastric cancer cell line sgc7901. Asian Pac J Cancer Prev, 14, 4685-88.

Zhang X, Yue P, Page BD, et al (2012). Orally bioavailable smallmolecule inhibitor of transcription factor Stat3 regresses human breast and lung cancer xenografts. Proc Natl Acad Sci USA, 109, 9623-8. 